\title{
Nanostructuring of 1-butyl-4-methylpyridinium chloride in ionic liquid-iron oxide nanofluids
}

\author{
Aswathy Joseph $^{1} \cdot$ Jacek Fal $^{2} \cdot$ Gaweł Żyła $^{2}$ (D) $\cdot$ Suresh Mathew ${ }^{1}$
}

Received: 17 May 2018 / Accepted: 21 June 2018/Published online: 5 July 2018

(C) The Author(s) 2018

\begin{abstract}
Understanding the behavior of ionic liquids (ILs) in ionic liquid-based nanofluids has great significance for its proper application. The phase changes and solidification observed in most ILs offer a great challenge to nanoparticles stabilization. Herein, we have synthesized and characterized a new type of IL-based iron oxide nanofluids using 1-butyl-4methylpyridinium chloride. We have investigated the formation of dendrite-like nanostructures by 1-butyl-4-methylpyridinium chloride at the IL-nanoparticle interface. This solidification induced under high electric field was nanoparticle size dependent and may be controlled by temperature and frequency changes. Examining the rheological behavior showed that higher volume fraction of nanoparticles in this nanofluids drastically decreased the flow viscosity causing a crossover from non-Newtonian (pure IL) to Newtonian and then to shear-thinning behavior. The nanofluid stability also decreased with the increase in nanoparticle size.
\end{abstract}

Keywords Nanofluid · Ionic liquid · Ionanofluids · Viscosity

\section{Introduction}

The formation of nano- or microstructural organizations in ILs has an influential effect on their physicochemical properties and performance in various applications [1]. The root cause of these structural organizations is different kinds of inter-molecular forces acting a different extent among the ions. Different modes of interactions between an anion and a cation $\Pi$ system can be observed in an IL. Some of them include (1) H-bonding between the hydrogens of the positively charged organic cation and the highly

Gaweł Żyła

gzyla@prz.edu.pl

Aswathy Joseph

aswathyj@gmail.com

Jacek Fal

jacekfal@prz.edu.pl

Suresh Mathew

sureshmathewmgu@gmail.com

1 School of Chemical Sciences (SCS), Mahatma Gandhi University, Kottayam, Kerala, India

2 Department of Physics and Medical Engineering, Rzeszow University of Technology, Rzeszow, Poland electronegative atoms of the anions, (2) X-bonding contributed by the halogen atoms present in the anions, (3) strong non-covalent anion- $\Pi$ interactions, in which the anion will be located above the center of the cationic ring, (4) weak non-covalent anion- $\Pi$ interactions, where the anion will be present outside the periphery of the $\Pi$-system and (5) steric interactions. The occurrence of nanostructural organization in certain ILs and IL-solvent/solute mixtures has been previously confirmed from molecular simulations and spectroscopic investigations [2]. The intermolecular forces and asymmetric nature of ions in ILs cause these nanostructural organizations leading to an ionic network or ion channels. Longer alkyl side chains (greater than or equal to $\mathrm{C}_{4}$ ) can cause the segregation of polar and nonpolar domains [3, 4]. Besides, with a strong nanostructural organization tendency, many ILs are also used as a template or a surfactant for template-assisted, shapecontrolled synthesis of different nanostructures [5].

However, the tendency of IL for nanostructuring can be disadvantageous also for some applications. For instance, some research groups working on imidazolium IL-based electrospray thrusters for nanopropulsion systems report the formation of radiation-induced needlelike or dendritic structures by ILs [6]. This reportedly affected the smooth 
functioning of the electrospray thrusters in the presence of an electric field. This phenomenon was the result of ILs becoming aligned with the electric field and subsequently being solidified by the electron beam. Therefore, the formation of nano- or microstructural organizations and ion channels in ILs has an influential effect on the performance of various IL-based functional materials [1]. These nanostructural organizations also highly enhance its electrical conductivity. It is crucial to understand the phase behavior and flow properties at its interface with a solid surface in order to undermine its applicability in devices like electrospray thrusters, solar cells, functional material synthesis, or for its use as lubricants in nano-/microelectromechanical systems (MEMS). However, within a family of ILs, the strength of all these interactions may vary depending on the nature of the type of ion pairs present in them. The occurrence of nanostructural organization and segregated polar/nonpolar domains in IL has been previously reported based on molecular simulations and spectroscopic investigations [2-4].

Here, we report a similar behavior in stable nanofluids of 1-butyl-4-methylpyridinium chloride-iron oxide systems. Ionic liquid nanofluids are under intensive investigation recently [7-11], and it is caused because many potential application of those types of liquid systems [12-16]. The nanoparticle size-dependent nanostructuring of IL layers at the IL-nanoparticle interface in these nanofluids systems were observed from HR-TEM images. We have further investigated the viscosity of these systems (Fig. 1).

\section{Experimental}

\section{Synthesis}

The nanofluids were prepared by the one-step MW irradiation of a mixture of 1-butyl-4-methylpyridinium chloride (IL), $\mathrm{FeSO}_{4}$ heptahydrate precursors and aqueous ammonia

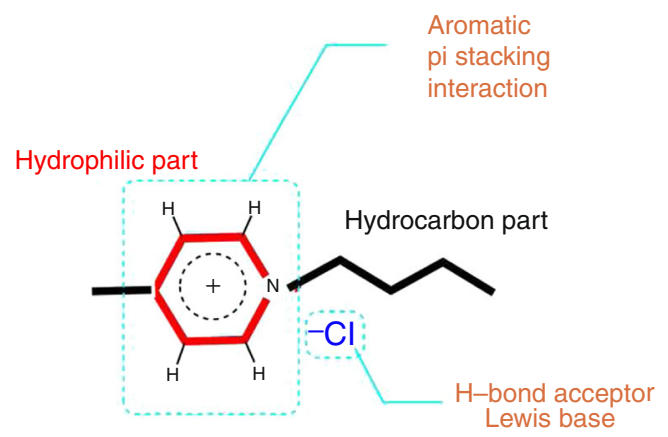

Fig. 1 Structural representation of 1-butyl-4-methylpyridinium chloride ionic liquid showing the different types of interactions in it
(25 mass \%) in a 10-mL standard borosilicate glass vials sealed with PTFE-coated silicon septum at $373.15 \mathrm{~K}$ for $10 \mathrm{~min}$ at $900 \mathrm{rpm}$ stirring speed. The reaction was carried out in an Anton Paar Monowave 300 microwave reactor. To increase the size of the iron oxide nanoparticles formed, the amount of $\mathrm{FeSO}_{4}$ dissolved in IL was increased. Thus, 4, 6.8, 14.7 and 15.6 mass $\%$ of $\mathrm{FeSO}_{4} \cdot 7 \mathrm{H}_{2} \mathrm{O}$ precursors were dissolved in IL. The samples are represented as B, C $\mathrm{D}$ and $\mathrm{E}$, respectively. Those information is summarized in Table 1.

\section{Characterization}

The high-resolution TEM images and nanoparticles SAED pattern were obtained using JEOL JEM-2100 microscope consisting thermionic gun with $101 \mu \mathrm{A}$ beam current at $200 \mathrm{kV}$ accelerating voltage. The XRD analysis of iron oxide nanoparticles was carried out using XPert PRO PANalytical X-ray diffractometer with $\mathrm{Cu} \mathrm{K} \alpha$ radiation.

Before rheological measurements, sample was subjected to mechanical stirring for $15 \mathrm{~min}$ in Genius 3 Vortex (IKA, Staufen, Germany) and ultrasonication in Emmi-60HC (EMAG, Moerfelden-Walldorf, Germany) for further $60 \mathrm{~min}$ to break possible nanoparticle agglomerates. Viscosity measurements were taken on the HAAKE MARS 2 rheometer (Thermo Fisher Scientific, Karlsruhe, Germany) with the minimum measurable torque of $0.5 \mu \mathrm{Nm}$, and all measuring points collected with lower torques were rejected. A coneplate measurement geometry with a diameter of $35 \mathrm{~mm}$ and $1^{\circ}$ cone angle was used, measuring gap was $0.054 \mathrm{~mm}$, and sample volume was $200 \mu \mathrm{L}$. Measurement geometry has been additionally isolated from the environment by using a Teflon solvent trap, and a constant temperature inside was maintained by a Peltier system connected to a Phoenix 2 (Thermo Fisher Scientific, Karlsruhe, Germany) thermostat. Viscosity and flow curves were determined by rotation measurement in control rate (CR) mode at a constant temperature of $20^{\circ} \mathrm{C}(293.15 \mathrm{~K})$ at shear rate range from 1 to $1000 \mathrm{~s}^{-1}$. The relative uncertainty of viscosity measurements in this system is $5 \%$ and was discussed elsewhere $[17,18]$. The dependence of dynamic viscosity on temperature was performed with a constant shear rate in temperature range from $20^{\circ} \mathrm{C}$ $(293.15 \mathrm{~K})$ to $60{ }^{\circ} \mathrm{C}(333.15 \mathrm{~K})$. Each measurement point was collected after $60 \mathrm{~s}$ of the stabilization of the temperature (temperature change rate: $1 \mathrm{~K} \mathrm{~min}^{-1}$ ). Before each series of experiments, a microstress control procedure was performed. This reduces the impact of microstresses resulting from the rheometer air bearing work. Each measurement stage was preceded by a temperature stability of the sample at the time of $300 \mathrm{~s}$. 
Table 1 Details of microwave irradiation conditions, mass percentage of precursor in IL used for nanofluid synthesis, nanofluid stability, nanoparticles size and nature

\begin{tabular}{|c|c|c|c|c|}
\hline Label & MW reaction conditions for ILMF synthesis & Precursor dissolved in IL (mass\%) & Stability & Nanoparticle size and nature \\
\hline $\mathrm{B}$ & $\begin{array}{l}\mathrm{FeSO}_{4} \cdot 7 \mathrm{H}_{2} \mathrm{O} / \mathrm{aq} \mathrm{NH}_{3} \\
\text { @ } 373.15 \mathrm{~K}, 10 \mathrm{~min}, 900 \mathrm{rpm}\end{array}$ & 4.03 & 20 days & $\begin{array}{l}5-10 \mathrm{~nm} \\
\text { Polydisperse not patchy }\end{array}$ \\
\hline $\mathrm{C}$ & $\begin{array}{l}\mathrm{FeSO}_{4} \cdot 7 \mathrm{H}_{2} \mathrm{O} / \mathrm{aq} \mathrm{NH}_{3} \\
\text { @ } 373.15 \mathrm{~K}, 10 \mathrm{~min}, 900 \mathrm{rpm}\end{array}$ & 6.83 & 1 week & $\begin{array}{l}10 \mathrm{~nm} \\
\text { Poly disperse, patchy }\end{array}$ \\
\hline $\mathrm{D}$ & $\begin{array}{l}\mathrm{FeSO}_{4} \cdot 7 \mathrm{H}_{2} \mathrm{O} / \mathrm{aq} \mathrm{NH} \mathrm{NH}_{3} \\
@ 373.15 \mathrm{~K}, 10 \mathrm{~min}, 900 \mathrm{rpm}\end{array}$ & 14.74 & Not stable & $\begin{array}{l}20 \mathrm{~nm} \\
\text { Highly polydisperse, not patchy }\end{array}$ \\
\hline $\mathrm{E}$ & $\begin{array}{l}\mathrm{FeSO}_{4} \cdot 7 \mathrm{H}_{2} \mathrm{O} / \mathrm{aq} \mathrm{NH} \\
\text { @ } 373.15 \mathrm{~K}, 10 \mathrm{~min}, 900 \mathrm{rpm}\end{array}$ & 15.63 & Not stable & $\begin{array}{l}20-50 \mathrm{~nm} \\
\text { Highly polydisperse not patchy }\end{array}$ \\
\hline
\end{tabular}

\section{Results and discussion}

\section{HR-TEM observations of nanofluids}

Among all the nanofluid samples, only $\mathrm{C}$ exhibited filament-like growth pattern at the interface region as can be seen in Fig. 2. This system exhibited an exceptional patchy pattern of the nanoparticles formed. This might be a result of IL molecular self-assemblies acting as a template for nanoparticle formation during microwave irradiation. The dendrite-like nanostructuring of ILs observed here has been influenced by the nanoparticles surface energy also, i.e., the excess energy of the surface atoms compared to that of the bulk. The tendency for IL molecules to self-assemble along the nanoparticle facets is influenced by the nanoparticles surface energy density. This surface energy density is highly dependent on the nanoparticles size. Two opposite trends of size-dependent surface energy density of nanomaterials have, however, been reported by different studies [19-21]. Yin Yao et al. reported that surface energy density decreases with the increase in nanoparticles size [22]. In another recent study by Wang et al., atomic simulations done to calculate the surface energy density of spherical nanosurfaces found that the average surface energy density almost remains constant once its radius exceeds $5 \mathrm{~nm}$ [21].

In B IL-iron oxide nanofluid, there is a dominant effect of repulsive solvation forces balancing the particle Brownian motion. This stabilized the nanosuspension to a greater extent, and the particles did not aggregate to a greater extent (Fig. 3a, b). The nanoparticles density in this system was relatively low when compared to $\mathrm{C}$ nanofluids. Also, no filament-like IL nanostructuring was observed at the nanoparticles interface region in this system. The SAED pattern shown in Fig. 3c indicated the
Fig. 2 HR-TEM image C ILiron oxide nanofluids $(\mathbf{a}-\mathbf{f})$; SAED pattern of iron oxide nanoparticles in $\mathrm{C}$ nanofluids (g). The images show formation of filament-like IL nanostructures at the ILnanoparticle interface and the formation of patchy iron oxide nanoparticle
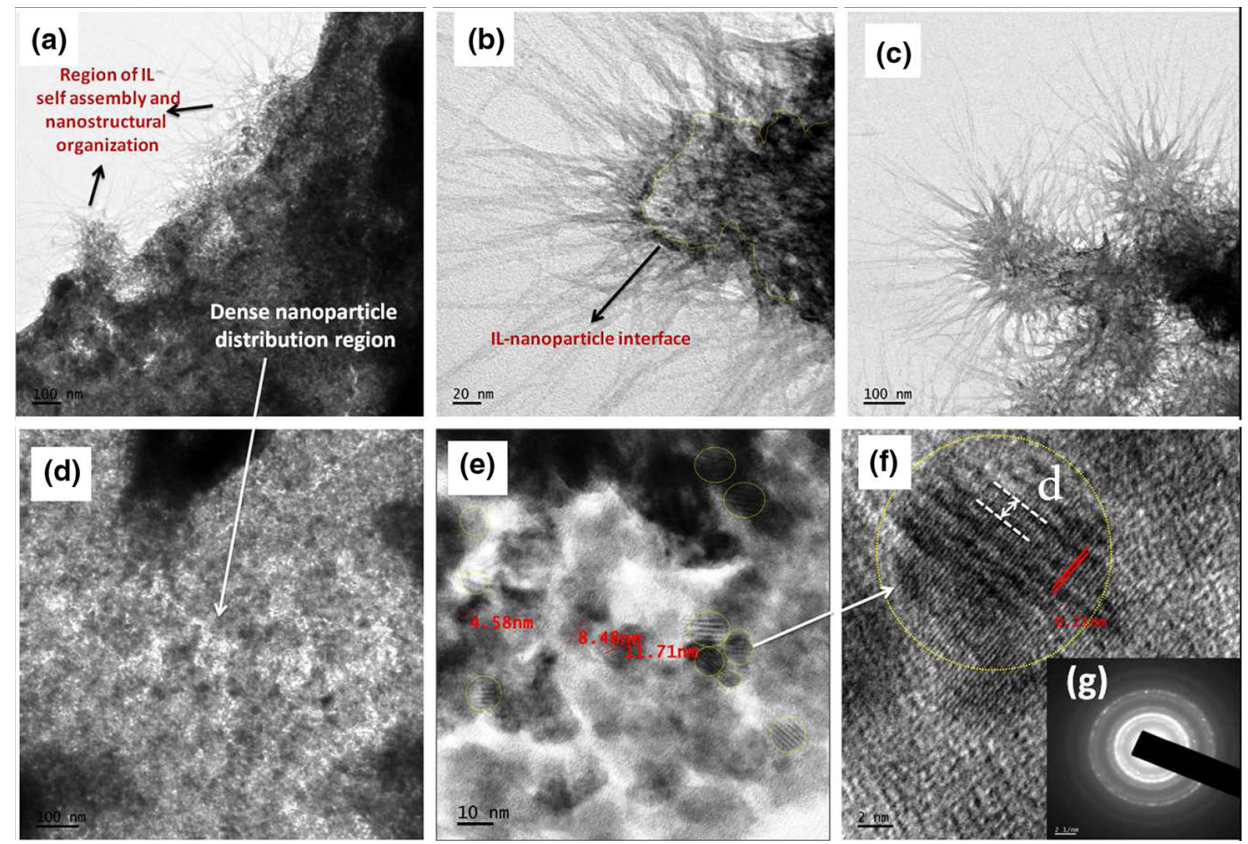

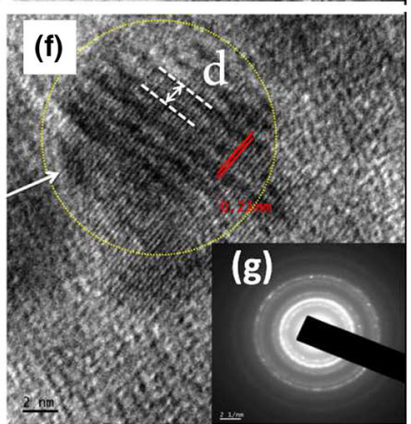


Fig. $3 \mathbf{a}$ and $\mathbf{b}$ are the HR-TEM images of B, c SAED of B, $\mathbf{d}$ and $\mathbf{e}$ are the HR-TEM and SAED of D, $\mathbf{f}-\mathbf{h}$ are HR-TEM images of $\mathrm{E}$ and $\mathbf{i}$ SAED of $\mathrm{E}$

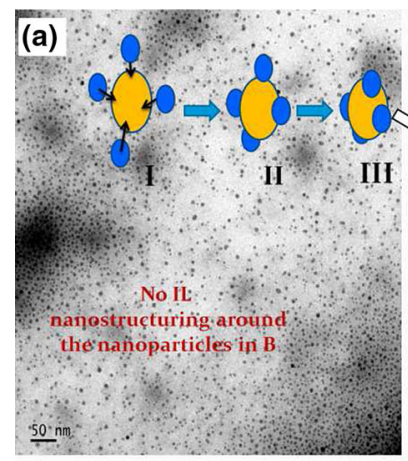

(b)
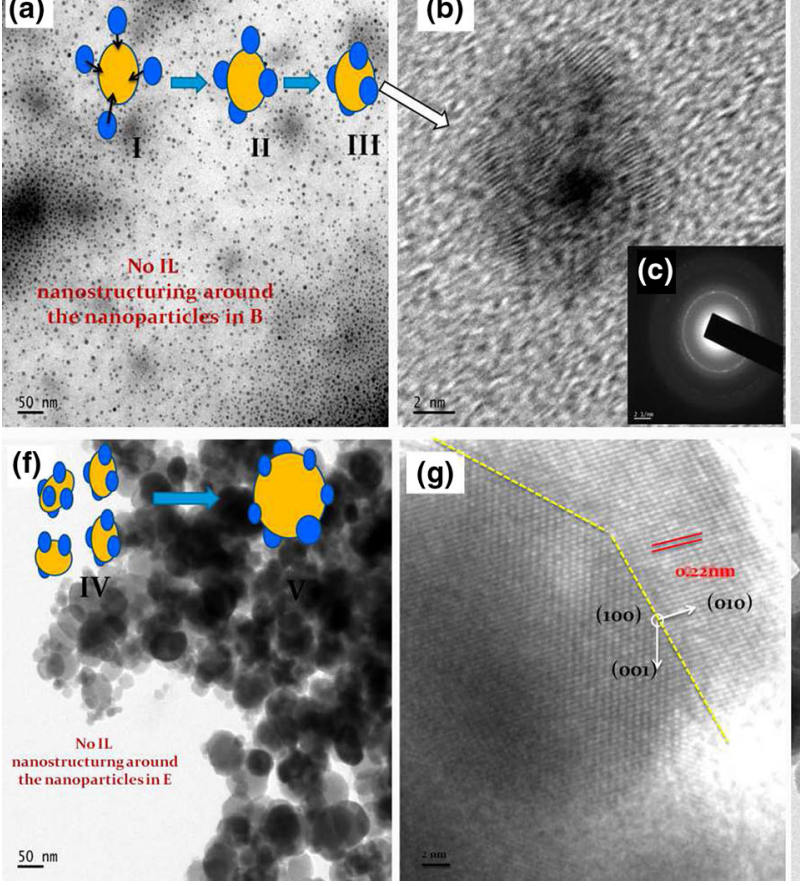

(g)

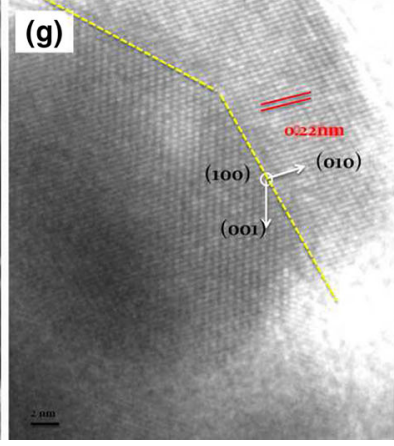

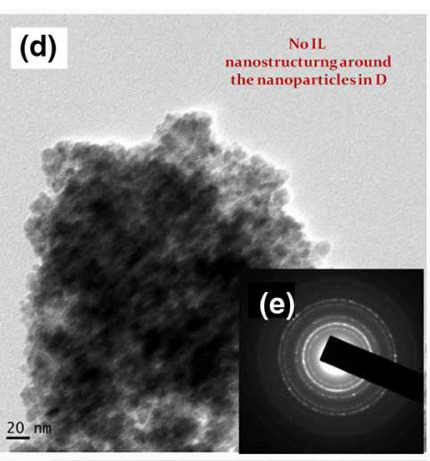

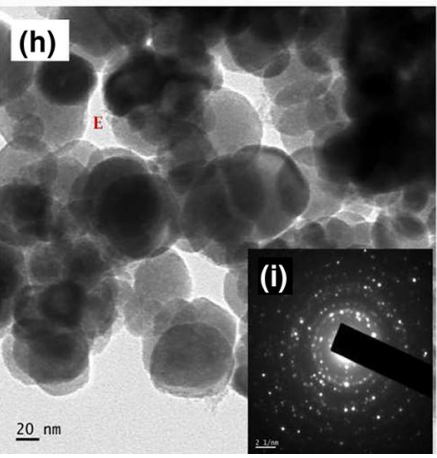

(a)

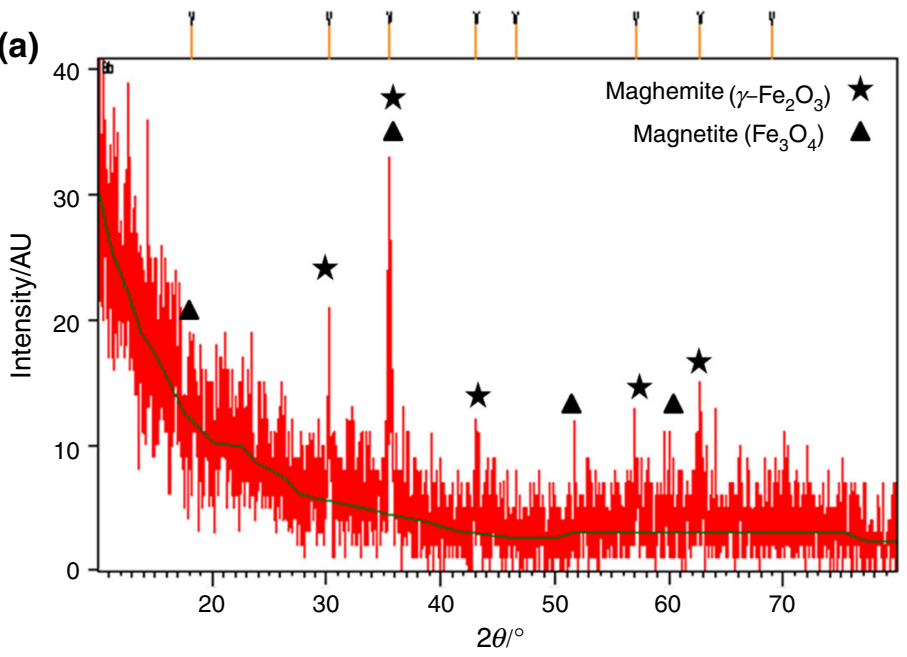

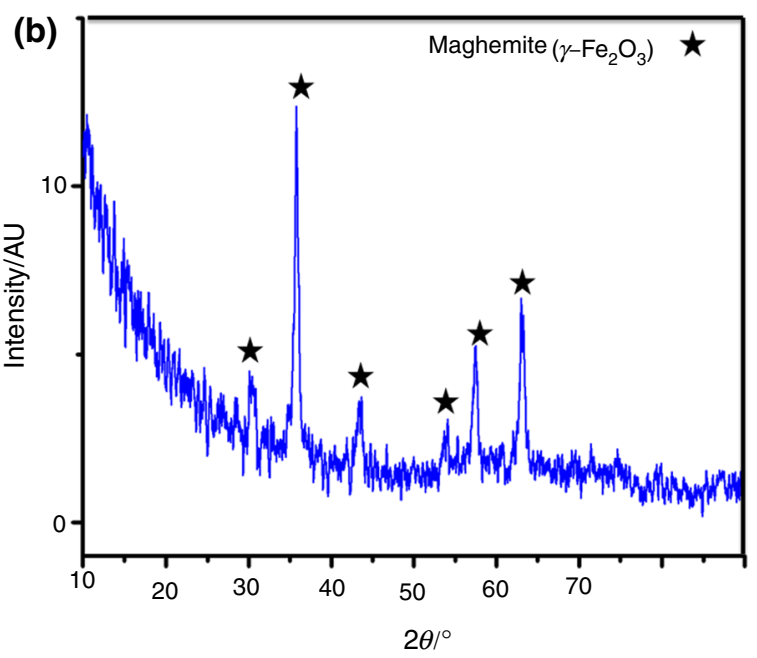

Fig. 4 Results of XRD measurements of iron oxide nanoparticles from C (a) and E (b) nanofluids

nanocrystalline nature of the particles in a 5 vol\% nanofluid. In D and E nanofluids, the particles were larger and highly agglomerated (Fig. 3d, f). In these systems also, IL nanostructuring was not observed. The XRD peaks of iron oxide nanoparticles separated from $\mathrm{C}$ and $\mathrm{E}$ sample was analyzed which is shown in Fig. 4. The XRD peaks of $\mathrm{C}$ indicated formation of a mixed phase iron oxide corresponding to that of magnetite (JCPDS-ICDD 19-629) and maghemite (JCPDS-ICDD 39-1346), whereas the XRD peaks of $\mathrm{E}$ indicated the maghemite $\left(\gamma-\mathrm{Fe}_{2} \mathrm{O}_{3}\right)$ phase of iron oxide with a nanoparticle percentage yield of $72.69 \%$. Obviously, increasing the mass $\%$ of $\mathrm{FeSO}_{4}$ precursor dissolved in IL ensured the phase purity of $\gamma-\mathrm{Fe}_{2} \mathrm{O}_{3}$ nanoparticles formed via microwave irradiation.

\section{Viscosity measurements}

We have further investigated the viscosity of these nanofluids at a low temperature of $20^{\circ} \mathrm{C}(293.15 \mathrm{~K})$ at which moderate frequency dependent, $\tan \delta$, variations are observed. The dynamic viscosity curves for different variants of the mass concentration of nanoparticles in IL were measured which is shown in Fig. 5. 

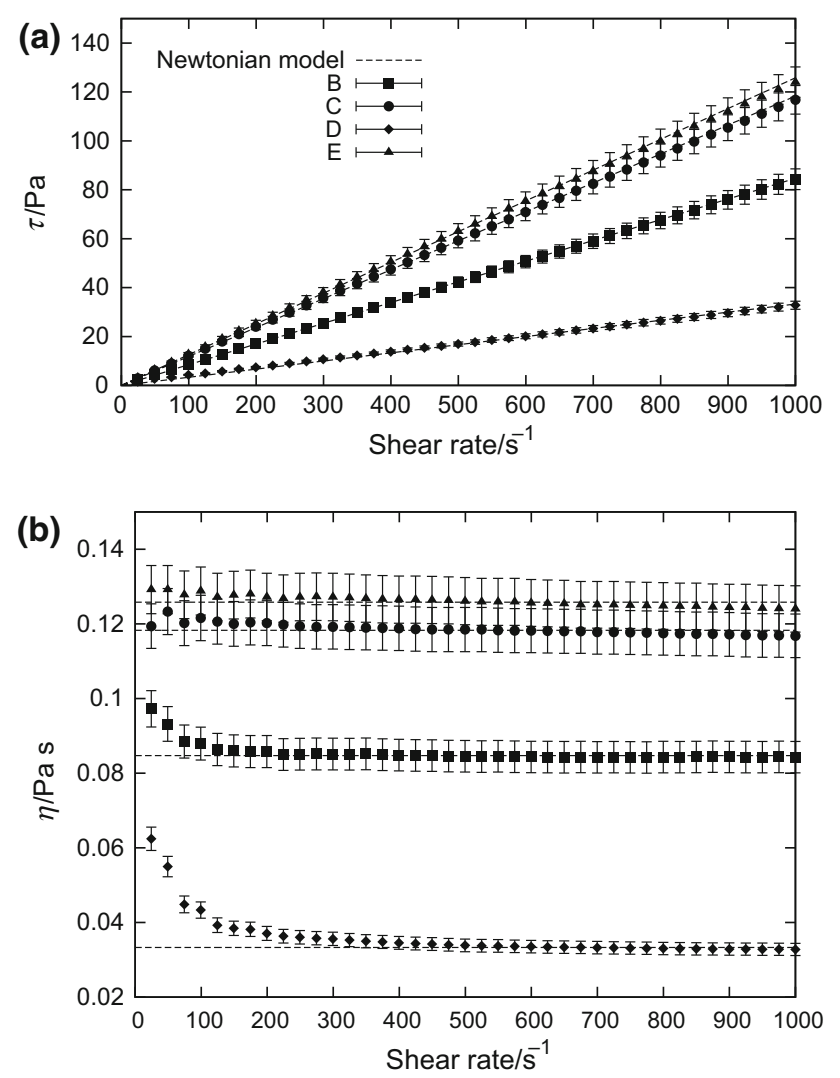

Fig. 5 a Flow and $\mathbf{b}$ dynamic viscosity curves of examined IL-iron oxide nanofluids samples at $20^{\circ} \mathrm{C}(293.15 \mathrm{~K})$

Basic model of viscosity is the model of ideal fluidNewtonian fluid. In such substances, the induced shear stress is proportional to the shear rate-viscosity is constant and does not dependent on shear rate, and might be described as:

$\tau=\eta \dot{\gamma}$,

where $\tau$ is shear stress, $\eta$ is viscosity and $\dot{\gamma}$ is shear rate. The dependence of the shear stress and viscosity on the shear rate of these nanofluids is shown in Fig. 5.

The pure ionic liquid is non-Newtonian. However, in these nanofluids, as the nanoparticles size is increased from $\sim 10 \mathrm{~nm}$ to over $50 \mathrm{~nm}$, a crossover from Newtonian to shear thinning typically occurs, especially at low shear rates. It might be noticed that $\mathrm{C}$ and $\mathrm{E}$ exhibit Newtonian nature, while $\mathrm{B}$ and $\mathrm{D}$ are non-Newtonian at a low shear rate. We might define limit shear rate above which each of this nanofluid has a Newtonian flow; it is 150 and $400 \mathrm{~s}^{-1}$ for $\mathrm{B}$ and D respectively, as presented in Fig. 5. Table 2 presents values of dynamic viscosity of samples in Newtonian flow shear rate range that is presented in Fig. 5.

Such a rheological behavior can be explained by the fact that mechanical forcing timescale is shorter than the relaxation time in the liquid [23]. The IL molecules
Table 2 Value of dynamic viscosity of examined nanofluids in Newtonian flow shear rate range

\begin{tabular}{ll}
\hline & $\eta / \mathrm{Pa} \mathrm{s}$ \\
\hline $\mathrm{B}$ & 0.0847 \\
$\mathrm{C}$ & 0.1183 \\
$\mathrm{D}$ & 0.0333 \\
$\mathrm{E}$ & 0.1258 \\
\hline
\end{tabular}

adsorbed on to the nanoparticles surface require greater relaxation time than the free ILs. This is at the expense of overcoming the IL-nanoparticle surface interaction energy. ILs with more bulky cations or larger alkyl chain length may exhibit higher viscosity. In lower viscosity ILs, the mass transport rates may be higher leading to collision and coalescence of the particles [24]. Therefore, the viscosity of ILs plays a major role in stabilizing these nanosuspensions.

Other than the alkyl chain length, the coordination ability and size of the IL anion could also influence the nanofluids stability as well as nanoparticles size in these systems [24-26]. According to DLVO theory, ILs can provide an electrostatic protection around the nanoparticles by forming an "electric shell" that can stabilize them. Moreover, the thickness of this shell depends on the IL molecular ion volume and the nanoparticles size [26]. Simulation studies show that a protective layer of supramolecular aggregates of anionic species comprises this protective layer [25, 27]. Imidazolium-based ILs have been previously reported to form this kind of supramolecular polymeric structures with a high degree of self-organization through weak H-bonding and pi-stacking interactions [28]. Aromatic pyridinium cations are expected to offer poor stability for nanoparticles in nanofluid suspension [24]. However, according to our investigation, 1-butyl-4-methylpyridinium chloride had a good ability for stabilization of $\gamma-\mathrm{Fe}_{2} \mathrm{O}_{3}$ nanoparticles without the use of additional surfactants or surface coatings.

Another factor to discuss here is the tendency of confinement of ILs among the nanoparticles. This is schematically illustrated in Fig. 6. In a more uniformly dispersed colloidal nanoparticle system where the particle size is approximately less than $10 \mathrm{~nm}$, the IL confinement can occur only as a result of self-organization forming supramolecular aggregates. This effect too can be controlled substantially by temperature conditions. IL molecules may shift its position as supramolecular aggregates itself. However, this shift depends on the viscous drag force between the IL network layers. In such a system, the particle Brownian motion is also significant if the magnetic dipolar interaction among the iron oxide nanoparticles is negligible. However, in a polydisperse nanofluid systems like D and E nanofluid, the particles aggregate due to the larger dipolar attraction and IL entrapment between the 
Fig. 6 Nanoconfinement effect occurring in colloidal suspensions of smaller monodisperse and larger polydisperse nanoparticles
Fig. 7 Dependence of viscosity on temperature of investigated IL-iron oxide nanofluids. Symbols are experimental points, lines-theoretical model
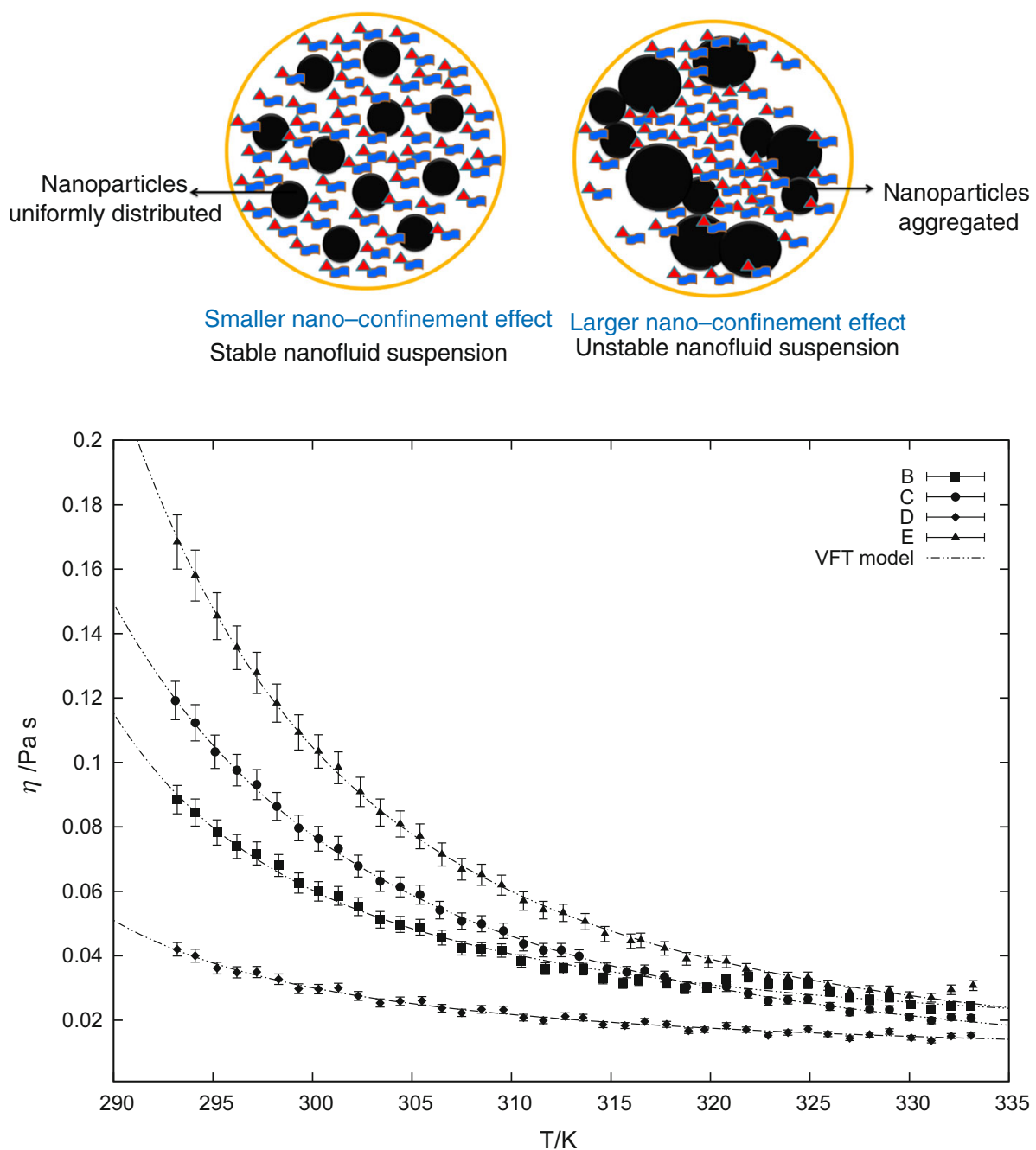

aggregates occur in a more confined space. High degree of confinement of ILs inside the colloidal suspension reduces the dynamic viscosity of these suspensions. In this case, ILs tightly squeezed in between the particles act as lubricating layers.

The D nanofluids were observed to be non-Newtonian shear-thinning fluid at $20^{\circ} \mathrm{C}(293.15 \mathrm{~K})$. Increasing the nanoparticles volume fraction in the IL after a limit gave a solid-like behavior. This solid-like behavior eventually attained is similar to that observed in a sheared supercooled system approaching glass transition [29]. It may be an indication that at $20^{\circ} \mathrm{C}(293.15 \mathrm{~K})$, the 1-butyl-4methylpyridinium chloride confined between the interfacial layer between the nanoparticles behaved as a supercooled liquid attaining a glassy state.

The temperature dependence of the dynamic viscosity for B, C, D and E nanofluids is shown in Fig. 7. It can be seen that the relationship shows an exponential behavior. However, the pattern shows certain deviations for B nanofluids at temperature after $318 \mathrm{~K}$ where there is a gradual increase in viscosity. Usually, on reaching glass transition, the viscosity of the material increases dramatically due to the rapid quenching of the temperature which results in giving amorphous liquid-like behavior [23]. For $\mathrm{E}$, the viscosity of the suspension was reduced drastically along with temperature and the nanoparticles were highly unstable also.

The experimental data were approximated using a Vogel-Fulcher-Tammann (VFT) expression:

$\ln (\eta)=A+\frac{B}{T-T_{0}}$,

where $A, B$ and $T_{0}$ are the fitting coefficients. Fitting parameters are presented in Table 3.

VFT can explain the temperature dependence of the zero-shear viscosity $\eta(T)$, but is not good for explaining behavior at high temperatures. In most cases, it can be applied successfully for a temperature range from experimental glass transition temperature $\left(T_{\mathrm{g}}\right)$ to $T_{\mathrm{g}}+100 \mathrm{~K}$ [30]. 
Table 3 Vogel-Fulcher-Tammann expression parameters for viscosity on temperature dependence of nanofluids

\begin{tabular}{llll}
\hline & $A /-$ & $B /-$ & $T_{0} / \mathrm{K}$ \\
\hline B & -4.858 & 85.408 & 258.337 \\
C & -7.460 & 414.199 & 215.495 \\
D & -5.162 & 68.5773 & 258.631 \\
E & -6.607 & 296.029 & 231.953 \\
\hline
\end{tabular}

\section{Conclusions}

The present paper deals with the synthesis and characterization of a new type of IL-based nanofluids synthesized using iron oxide nanoparticles synthesized in 1-butylpyridinium chloride by one-step in situ microwave reaction. The paper also investigates the field-induced nanostructuring of 1-butyl-4-methylpyridinium chloride in these nanofluids. The IL nanostructuring at the IL-nanoparticle interface is greatly influenced by the electric field, temperature and nanoparticles size. This phenomenon is a balanced play between the nanoparticles size-dependent surface energy and the IL tendency for field dependent selfassembly. In our investigation, nanostructuring of IL was observed in nanofluids with nanoparticle size of approximately $10 \mathrm{~nm}$. This was because of the electric field-induced IL assembly at the nanoparticles interface. On the other hand, inhibition of nanostructuring in nanofluids with nanoparticles too smaller than $10 \mathrm{~nm}$ may be due to the nanoparticles Brownian motion that attains sufficient energy for the breakage of IL ion channels created by weak inter-ionic forces, while in the case of nanofluids with particle size greater than $10 \mathrm{~nm}$, nanoparticles settled and phase separated from the IL. The temperature dependence of the viscosity of these nanofluids could be described using the Vogel-Fulcher-Tammann expression.

Acknowledgements We greatly acknowledge the financial assistance given by DST (DST/IND/POL/P-06/2014), Govt. of India and the Polish Ministry of Science and Higher Education through the IndoPoland Joint Research Project 2015-17. AJ also acknowledges the Jawaharlal Nehru Scholarship for Doctoral Studies (2015-17).

Open Access This article is distributed under the terms of the Creative Commons Attribution 4.0 International License (http://creative commons.org/licenses/by/4.0/), which permits unrestricted use, distribution, and reproduction in any medium, provided you give appropriate credit to the original author(s) and the source, provide a link to the Creative Commons license, and indicate if changes were made.

\section{References}

1. Chen S, Zhang S, Liu X, Wang J, Wang J, Dong K, Sun J, Xu B. Ionic liquid clusters: structure, formation mechanism, and effect on the behavior of ionic liquids. Phys Chem Chem Phys. 2014;16(13):5893-906.

2. Bardak F, Xiao D, Hines LG, Son P, Bartsch RA, Quitevis EL, Yang P, Voth GA. Nanostructural organization in acetonitrile/ ionic liquid mixtures: molecular dynamics simulations and optical Kerr effect spectroscopy. ChemPhysChem. 2012;13(7):1687-700.

3. Canongia Lopes JN, Padua AA. Nanostructural organization in ionic liquids. J Phys Chem B. 2006;110(7):3330-5.

4. Canongia Lopes JN, CostaGomes MF, Pádua AA. Nonpolar, polar, and associating solutes in ionic liquids. J Phys Chem B. 2006;110(34):16816-8.

5. Ding K, Miao Z, Liu Z, Zhang Z, Han B, An G, Miao S, Xie Y. Facile synthesis of high quality $\mathrm{TiO}_{2}$ nanocrystals in ionic liquid via a microwave-assisted process. $\mathrm{J}$ Am Chem Soc. 2007;129(20):6362-3.

6. King LB, Meyer E, Hopkins MA, Hawkett BS, Jain N. Selfassembling array of magnetoelectrostatic jets from the surface of a superparamagnetic ionic liquid. Langmuir. 2014;30(47):14143-50.

7. Wang B, Wang X, Lou W, Hao J. Rheological and tribological properties of ionic liquid-based nanofluids containing functionalized multi-walled carbon nanotubes. J Phys Chem C. 2010;114(19):8749-54.

8. Minea A-A, El-Maghlany WM. Natural convection heat transfer utilizing ionic nanofluids with temperature-dependent thermophysical properties. Chem Eng Sci. 2017;174:13-24.

9. França JMPM, Lourenço MJV, Murshed SS, Padua AAH, Nieto de Castro CA. Thermal conductivity of ionic liquids and ionanofluids and their feasibility as heat transfer fluids. Ind Eng Chem Res. 2018;57:6516-29.

10. Chereches EI, Sharma KV, Minea AA. A numerical approach in describing ionanofluids behavior in laminar and turbulent flow. Contin Mech Thermody. 2018;30(3):657-66.

11. Minea AA, Murshed SS. A review on development of ionic liquid based nanofluids and their heat transfer behavior. Renew Sustain Energy Rev. 2018;91:584-99.

12. Rogers RD, Seddon KR. Ionic liquids-solvents of the future? Science. 2003;302(5646):792-3.

13. Joseph A, Żyła G, Thomas VI, Nair PR, Padmanabhan AS, Mathew S. Paramagnetic ionic liquids for advanced applications: a review. J Mol Liq. 2016;218:319-31.

14. Zhang X, Pan L, Wang L, Zou J-J. Review on synthesis and properties of high-energy-density liquid fuels: hydrocarbons, nanofluids and energetic ionic liquids. Chem Eng Sci. 2018;180:95-125.

15. Vekariya RL. A review of ionic liquids: applications towards catalytic organic transformations. J Mol Liq. 2017;227:44-60.

16. He Z, Alexandridis P. Ionic liquid and nanoparticle hybrid systems: emerging applications. Adv Colloid Interface Sci. 2017;244:54-70.

17. Żyła G, Fal J. Experimental studies on viscosity, thermal and electrical conductivity of aluminum nitride-ethylene glycol (AlN-EG) nanofluids. Thermochim Acta. 2016;637:11-6.

18. Żyła G, Fal J. Viscosity, thermal and electrical conductivity of silicon dioxide-ethylene glycol transparent nanofluids: an experimental studies. Thermochim Acta. 2017;650:106-13.

19. Ouyang G, Wang C, Yang G. Surface energy of nanostructural materials with negative curvature and related size effects. Chem Rev. 2009;109(9):4221-47. 
20. Lu H, Jiang Q. Size-dependent surface energies of nanocrystals. J Phys Chem B. 2004;108(18):5617-9.

21. Wang J, Bian J, Niu X, Wang G. A universal method to calculate the surface energy density of spherical surfaces in crystals. Acta Mech Sin. 2017;33(1):77-82.

22. Yao Y, Wei Y, Chen S. Size effect of the surface energy density of nanoparticles. Surf Sci. 2015;636:19-24.

23. Bou-Malham I, Bureau L. Nanoconfined ionic liquids: effect of surface charges on flow and molecular layering. Soft Matter. 2010;6(17):4062-5.

24. Richter K, Birkner A, Mudring A-V. Stability and growth behavior of transition metal nanoparticles in ionic liquids prepared by thermal evaporation: How stable are they really? Phys Chem Chem Phys. 2011;13(15):7136-41.

25. Oliveira FC, Rossi LM, Jardim RF, Rubim JC. Magnetic fluids based on $\gamma-\mathrm{Fe}_{2} \mathrm{O}_{3}$ and $\mathrm{CoFe}_{2} \mathrm{O}_{4}$ nanoparticles dispersed in ionic liquids. J Phys Chem C. 2009;113(20):8566-72.

26. Bansal V, Bhargava SK. Ionic liquids as designer solvents for the synthesis of metal nanoparticles. In: Ionic liquids: theory, properties, new approaches, InTech. 2011.
27. Krämer J, Redel E, Thomann R, Janiak C. Use of ionic liquids for the synthesis of iron, ruthenium, and osmium nanoparticles from their metal carbonyl precursors. Organometallics. 2008;27(9):1976-8.

28. Rodriguez-Arco L, Gomez-Ramirez A, Duran JD, Lopez-Lopez MT. New perspectives for magnetic fluid-based devices using novel ionic liquids as carriers. In: Smart actuation and sensing systems-recent advances and future challenges, Intech. 2012.

29. Siebenbürger M, Fuchs M, Winter H, Ballauff M. Viscoelasticity and shear flow of concentrated, noncrystallizing colloidal suspensions: comparison with mode-coupling theory. J Rheol. 2009;53(3):707-26.

30. Garca-Coln L, Del Castillo L, Goldstein P. Theoretical basis for the Vogel-Fulcher-Tammann equation. Phys Rev B. 1989;40(10):7040. 